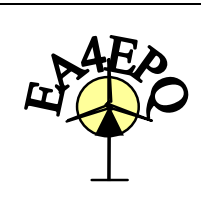

\title{
Asynchronized turbogenerators and compensators for improving the electric power quality
}

\author{
N. Pinchuk, O. Antonyuk, M. Roytgarts \\ Branch Electrosila of the JSC Power Machines \\ 139, Moskovsky pr., 196105, Saint-Petersburg, Russia \\ Fax number: +7(812) 388 1814, Phone number: +7(812) 387 4788, e-mail: roitgarts@elsila.spb.ru, $\underline{\text { mroytgarts@yandex.ru }}$
}

\begin{abstract}
Results of new air-cooled asynchronized turbogenerators development of power 110-320 MW and compensators 100 Mvar with double-way feed having the improved operational characteristics in comparison with traditional generators and compensators are presented.
\end{abstract}

\section{Key words}

(Asynchronized turogenerator, compensator, capability)

\section{Introduction}

Since the 90s the problem of maintaining the required level of voltages in the high-voltage lines has become more acute for the power systems of the Russian Federation. This is due to the lack of proper facilities for the reactive power compensation in the 220 to $500 \mathrm{kV}$ lines which are characterized by long extension and seasonal underloading. For example, the voltages in the $500-\mathrm{kV}$ lines have reached 528 to $552 \mathrm{kV}$ with the admissible operating voltage as per Russian standards being equal to $525 \mathrm{KV}$.

Under the abovementioned conditions the personnel of the electric power stations is compelled to transfer the synchronous turbogenerators into the reactive power consumption mode, which fact permits to somewhat lower the overvoltages but causes the accelerated wear of turbogenerators.

One way of solving this problem is to use of the asynchronized turbogenerators belonging to the doublefed electric machines. The asynchronized turbogenerators have the higher static and dynamic stability when operating under the reactive power consumption modes as well as the improved design of the stator end zone that ensures decrease of the core end heating.

A convenient way out to eliminate this problem is the installation of electric-machine reactive power compensators for regulation of reactive power within a wide range. The electric-machine compensators, in the contrary with the electrostatic ones built up on the basis of the up-to-date power electronics, do not contribute any distortions into the system current and voltage curves, moreover, they improve the progress of dynamic processes in the network due to influence of the rotating masses of the compensator.

The electric-machine compensators allow increasing for a short time up to a double rated value the generation of reactive power under dynamic modes when this power varies very quickly. The modern principles of asynchronized control applied to the asynchronized electric-machine compensators allow ensuring the operation of the nonsalient -pole compensator at equal values of output and consumed reactive power.

The concept of the asynchronized generator was proposed by the World Chess Champion Mikhail M. Botvinnik in the 50s of the previous century and was realized in practice in Russia on the hydrogenerators in the $60 \mathrm{~s}$ and on the water-hydrogen cooled turbogenerators of Kharkov plant Electrotyazgmash make in 1985. These turbogenerators for more than 20 years have been under successful operation at the Burshtynskaya Regional Thermal Power Plant (in Ukraine).

The prototype of type T3ФA-110-2 asynchronized turbogenerator with an output capacity of $110 \mathrm{MW}$ is under continuous operation at the electric power station in Moscow since 2003. In 2007 the type ТЗФАУ-160-2-turbogenerators with a power capacity of $160 \mathrm{MW}$ and the type ТЗФСУ-160-2 turbogenerators with a power capacity of 320 MW were also manufactured for the JSC Mosenergo (Fig.1).

The air-cooled asynchronized turbogenerators and compensators of Electrosila make are of the core and stator winding traditional design, with the updated design 


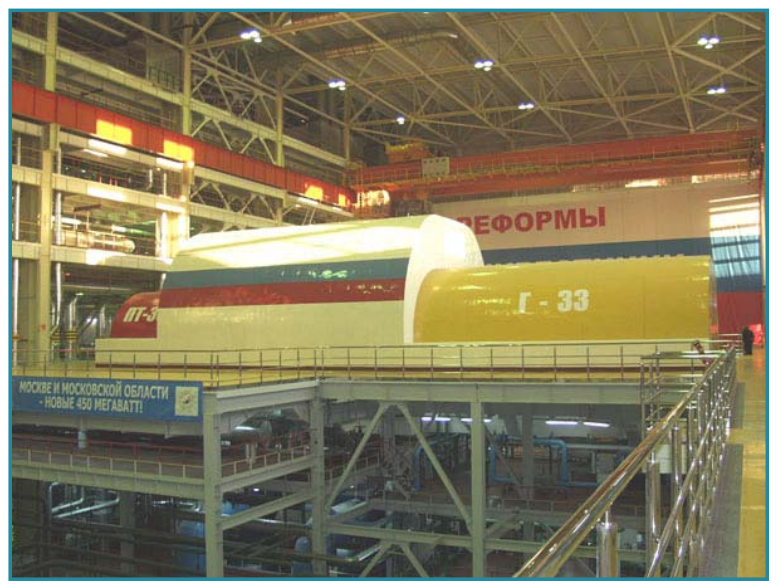

Fig. 1. Asynchronized turbogenerator of $160 \mathrm{MW}$ on the Moscow Power Station

of the pressure plate in the end zone, that ensures the highly efficient cooling under the reactive power consumption operating modes.

The design of the nonsalient-pole rotor distinguishes in the availability of two on 90 electrical degree shifted field windings connected to two pairs of slip rings. The field windings are power supplied from two reversible static thyristor excitation systems. Not only two, but several windings (of the polyphase winding) may be arranged on the rotor.

In the asynchronized turbogenerators the independent field windings permit to change both the value and the position of the resulting excitation magnetic flux with respect to the turbogenerator rotor longitudinal and quadrature axes.

The excitation magnetic flux is controlled by the microprocessor-based automatic voltage regulator and by the thyristor exciter amplitude-phase control system, which receive the information both about the stator voltage and current and about the rotor angular position. Excitation system permits to control the field currents independently under the steady-state mode as well as under the forcing mode of operation.

The distinguishing feature of the classic asynchronized turbogenerator the rotor of which is fitted out with two shifted windings having the similar number of ampereturns consists in the improved reliability due to the opportunity of operation with a decreased power in case of one of two windings or excitation systems failure. The asynchronized turbogenerator with one rotor winding may be operated as a traditional synchronous turbogenerator with the load decrease up to $70 \%$ of the rated power.

The turbogenerator with the similar number of ampereturns in the rotor windings being short-circuited can operate under the asynchronous duty. In this case the permissible load amounts to $60 \%$ to $70 \%$ of the rated power. The permissible slip under the asynchronous duty equals to fractions of one percent.
Consequently, the asynchronized turbogenerators and compensators permit to decrease the number of reactors and regulated reactive-power compensators used at the electric power stations, to improve the quality of electric energy in the power systems, to increase the limits of static and dynamic stability of electric power stations, to decrease the reactive-power loads upon the synchronous turbogenerators operating in parallel and, thus, to improve their reliability and service life. The important advantage of the asynchronized turbogenerators as compared with the static compensating converter substations consists in the practically sine-wave shape of the output voltage. No special circuit designs, filters, reactors and other devices that decrease the content of higher harmonics in the power system are needed for the asynchronized turbogenerators and compensators.

\section{Design Features of the Asynchronized Turbogenerators and Compensators}

When two or several windings with magnetic axes shifted along the rotor circumference are arranged on the rotor, their magnetizing forces are added not algebraically, but geometrically. The resulting magnetizing force of two identical windings arranged at a angle of $90^{\circ}$ is not 2 times more, but $\sqrt{2}$ times more than the magnetizing force of one winding. That is why the number of ampereturns arranged on the rotor shall be $\sqrt{2}$ times more than those to be installed in the synchronous machine. This results in the increase of the diameter, line current load and losses in the rotor and requires the effective cooling in the slot and end portions of the winding.

Another distinctive feature of the classic asynchronized machine rotor design is the use of the coil winding laid into the slots of different depth. Laid in the shallow slots are the coils of one phase, while laid in the deep slots are the coils of two phases. Shown in Fig. 2 is the crosssectional sketch drawing of type T3ФA-110 asynchronized turbogenerator that provides the active power of $110 \mathrm{MW}$ with a power factor of 0.95 . Fig. 3 shows the rotor in the process of the winding laying. The spatial location and the ratio of the numbers of deep and shallow slots determines the magnetic field spectral distribution in the air gap and on the stator surface, influences upon the value of stray loss and stator heating.

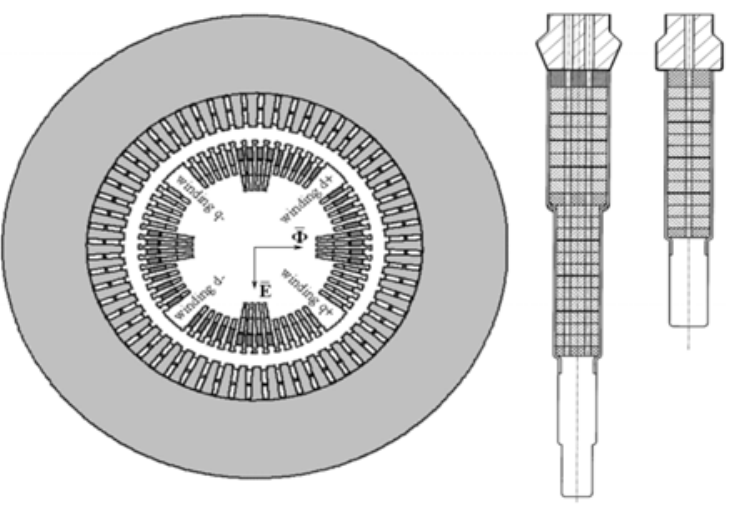

Fig. 2. Cross section of the T3ФA-110-2 turbogenerator active zone and the rotor slots 


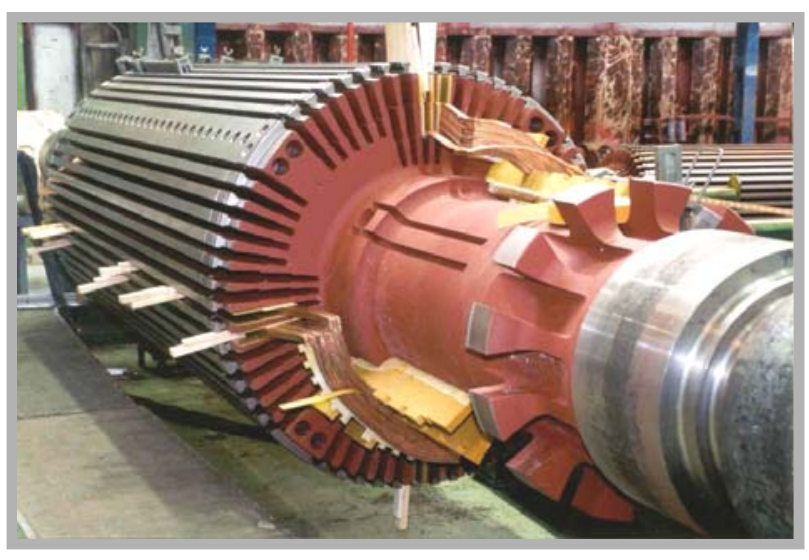

Fig. 3. Asynchronized turbogenerator rotor in the process of the winding laying

TABLE 1. Spectral Distribution of Magnetic Field in the Air Gap for the Asynchronized Turbogenerator

\begin{tabular}{|c|c|c|c|c|c|c|c|}
\hline \multicolumn{2}{|c|}{ Variant } & $\begin{array}{l}\frac{\mathrm{A}_{3}}{\mathrm{~A}_{1}} \\
\%\end{array}$ & $\begin{array}{l}\frac{A_{5}}{A_{1}} \\
\%\end{array}$ & $\begin{array}{l}\frac{A_{7}}{A_{1}} \\
\%\end{array}$ & $\begin{array}{l}\frac{\mathrm{A}_{9}}{\mathrm{~A}_{1}} \\
\%\end{array}$ & $\begin{array}{l}\frac{A_{11}}{A_{1}} \\
\%\end{array}$ & $\sum_{\mathrm{k}=3}^{65}\left(\frac{\mathrm{kB}_{\delta_{\mathrm{k}}} \mathrm{k}_{\tau_{\mathrm{k}}}}{\mathrm{B}_{\delta_{1}}}\right)^{2}$ \\
\hline \multirow{3}{*}{$\begin{array}{l}16 \text { deep } \\
\text { slots, two } \\
\text { windings } \\
\text { are in } \\
\text { operation }\end{array}$} & $\begin{array}{c}\text { MMF } \\
\text { spectrum, } \\
\text { open } \\
\text { circuit }\end{array}$ & 1.45 & 8.0 & 0.22 & 0.37 & 2.2 & \\
\hline & $\begin{array}{c}\mathrm{B}_{\delta} \\
\text { spectrum, } \\
\text { open } \\
\text { circuit }\end{array}$ & 12.5 & 2.1 & 1.1 & 0.67 & 2.5 & 0.2 \\
\hline & $\begin{array}{c}c \mathrm{~B}_{\delta} \\
\text { spectrum, } \\
\text { rated load }\end{array}$ & 7.9 & 7.8 & 2.5 & 2.0 & 3.2 & 0.35 \\
\hline \multirow{2}{*}{$\begin{array}{l}24 \text { deep } \\
\text { slots, two } \\
\text { windings } \\
\text { are I } \\
\text { operation }\end{array}$} & $\begin{array}{c}\text { MMF } \\
\text { spectrum, } \\
\text { open } \\
\text { circuit }\end{array}$ & 5.52 & 6.41 & 0.86 & 1.73 & 1.68 & \\
\hline & $\begin{array}{c}\mathrm{B}_{\delta} \\
\text { spectrum, } \\
\text { open } \\
\text { circuit }\end{array}$ & 23.7 & 1.3 & 1.4 & 1.7 & 2.6 & 0.59 \\
\hline \multirow{3}{*}{$\begin{array}{c}16 \text { deep } \\
\text { slots, one } \\
\text { winding is } \\
\text { in } \\
\text { operation }\end{array}$} & $\begin{array}{c}\text { MMF } \\
\text { spectrum, } \\
\text { open } \\
\text { circuit }\end{array}$ & 1.45 & 8.0 & 0.22 & 0.37 & 2.2 & \\
\hline & $\begin{array}{c}\mathrm{B}_{\delta} \\
\text { spectrum, } \\
\text { open } \\
\text { circuit }\end{array}$ & 2.7 & 1.6 & 2.6 & 1.3 & 2.5 & 0.10 \\
\hline & $\begin{array}{c}\mathrm{B}_{\delta} \\
\text { spectrum } \\
\mathrm{P}=80 \\
\mathrm{MW}, \\
\operatorname{Cos}(\varphi)=1 . \\
0\end{array}$ & 12.7 & 6.6 & 3.5 & 1.4 & 3.0 & 0.39 \\
\hline
\end{tabular}

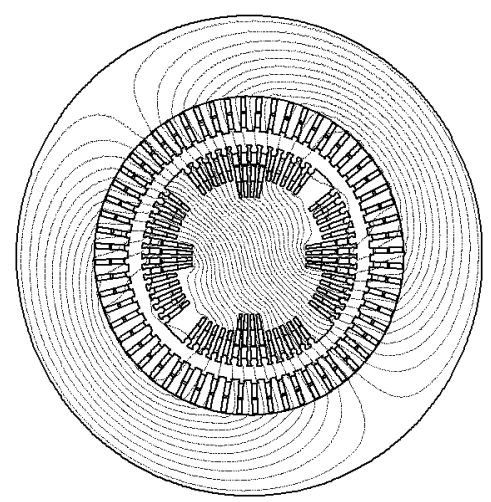

$\mathrm{B}_{\boldsymbol{b}}$, Тл

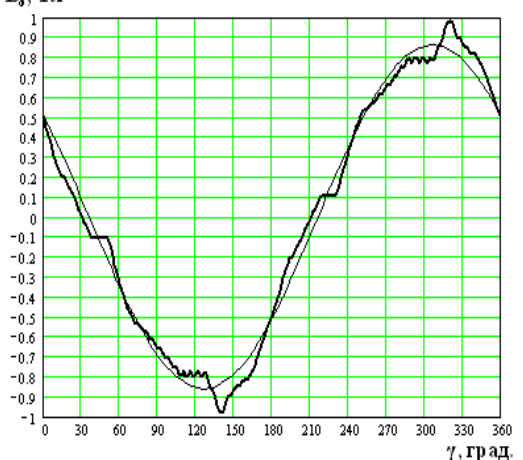

a) Power supply of two field windings under load duty
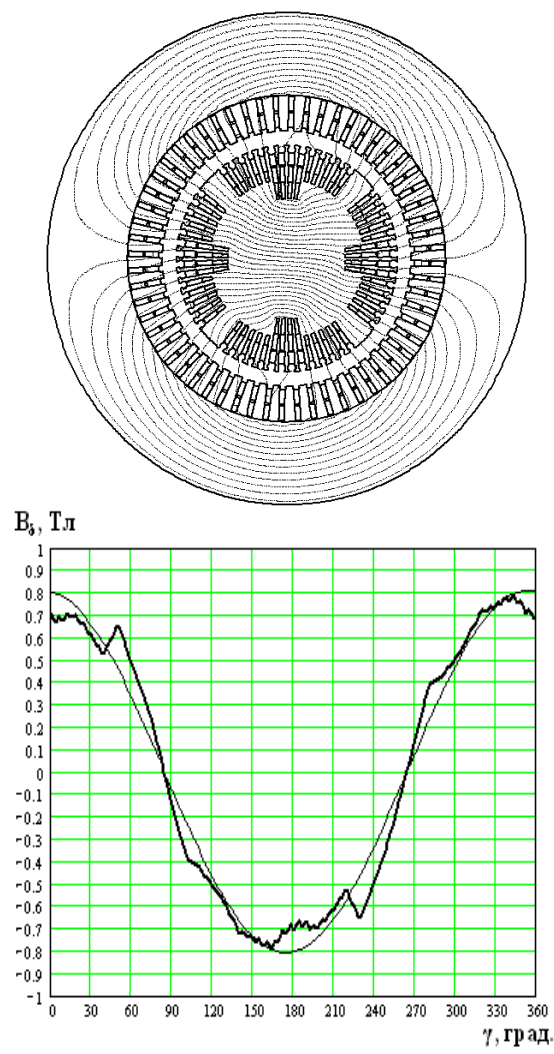

b) Power supply of one filed winding under the load duty $\mathrm{P}=83.5 \mathrm{MWT}, \cos \varphi=1.0$

Fig. 4..Field patterns and magnetic flux density distribution along the air gap circumference for the Т3ФA-110-2 turbogenerator operating under load 
Shown in Table 1 is the spectral distribution of magnetizing force and magnetic field density in the air gap as well as the stator teeth losses with the two rotor windings being supplied with the similar current. From the Table we notice that in case of 24 deep slots the field spectral distribution is worse and the stray losses are higher than in case of 16 deep slots. The change of the load conditions as well as the disconnection of one of two field windings causes the change of the magnetic axis position with respect to the axis of symmetry of deep slots and the field spectral distribution, and the stray losses in the stator change respectively (Fig. 4). The radical way of reducing the losses due to the excitation field higher harmonics is the increase of the air gap between the rotor and stator. This results in the additional increase of currents and losses in the asynchronized turbogenerator field windings. For example in the type Т3ФA-110-2 asynchronized turbogenerator the current linear load exceeds by $30 \%$ and the current density almost by $50 \%$ exceeds the corresponding parameters of the $110 \mathrm{MW}$ synchronous generator.

As the practice of the synchronous turbogenerators operation shows, the overheating of the end zone parts may take place in the underexcitation duty. In this connection, the asynchronized turbogenerator stator end zone has been specially designed to provide the high reliable and effective ventilation under all operating conditions.

Thus, the classical asynchronized turbogenerator with the symmetrical field windings has a little bit higher overall dimensions and the lower efficiency as well as requires the higher labour input for its manufacture as compared with those for the traditional synchronous turbogenerator of the same rated power capacity. However, in the underexcitation duties these disadvantages are covered by the doubtless advantages available with the asynchronized turbogenerators.

The next step in developing the asynchronized turbogenerators design was the use of the so called "control" winding that creates the magnetic flux along the quadrature axis; this winding being located in the turbogenerator rotor big tooth. Though the magnetizing force of this winding amounts to about $10 \%$ of that of the main winding, with the availability of the up-to-date excitation systems this value will be enough to turn the resulting magnetic flux and to maintain the stability in the deep underexcitation duties. The asynchronized turbogenerators fitted out with the main and control windings have the relatively less masses and overall dimensions and higher efficiencies than the asynchronized turbogenerators fitted out with the two symmetrical field windings. Such generators can operate with the short-circuited field winding, but they have no proper duplication for two windings as it takes place in the machines with the symmetrical windings. The type ТЗФУ-160-2 asynchronized turbogenerators with an output capacity of $160 \mathrm{MW}$ and type ТЗФСУ-320-2 asynchronized turbogenerators with an output capacity of $320 \mathrm{MW}$, both fitted out with the control winding, have been created at Electrosila.

\section{Comparison of the Asynchronized Machine and Synchronous Machine Characteristics}

The major advantages of the asynchronized turbogenerator are supported by its capability curves. Fig. 5 shows the curves determining the admissible active and reactive loads when two field windings are power supplied with a identical rated current (curve 1), when one field winding is energized and the other is shortcircuited (curve 2) as well as when one and two field windings are operating under the synchronous duty (curve 3). Symbol $\boldsymbol{n}$ designates the point of the rated duty.

When moving along the curve an the limit load is determined by the field current in two windings, when moving further counterclockwise (.)c - the static stability limit under the synchronous generator mode is determined, and further the operating zone for the asynchronized turbogenerator is limited by curve $\boldsymbol{c b}$, while that for the synchronous turbogenerator is limited by curve $c c$ '. With only one field winding being energized, the capability curve is limited by the dashed curve 2. Curve $\boldsymbol{d m} \boldsymbol{f}$ corresponds to the field current limiting value, and in this case the curve portion $\boldsymbol{d m}$ is the overexcitation mode, while further it presents the underexcitation mode, the curve section $\boldsymbol{f k}$ limits the zone of the stator maximum permissible current and curve section $\boldsymbol{k} \boldsymbol{k}^{\prime}$ corresponds to the static stability limit.

From the capability curves it is seen that the asynchronized turbogenerator has no static stability limit and admits the higher reactive load in the underexcitation mode than in the overexcitation mode. The same machine operating in a synchronous generator mode, for example, with two field windings being connected in series or with one field winding being disconnected or short-circuited, is limited in its static stability when operating in the underexcitation mode.

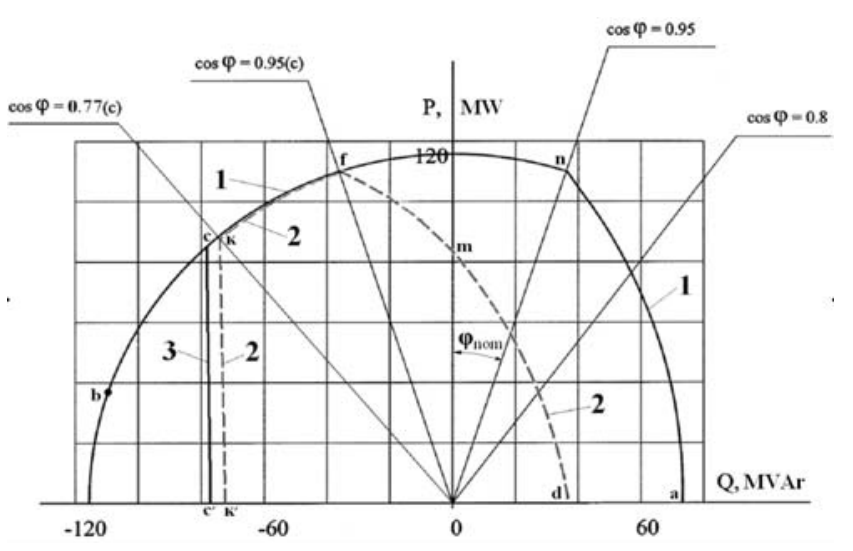

1 - two field windings are in operation

2 - one field winding is in operation

3 - synchronous duty with limitation on $\theta=90^{\circ}$

Fig.5. Asynchronized and synchronous capability curves 


\section{Main Characteristics of Asynchronized Compensator 100 Mvar}

The modern principles of asynchronized control for synchronous machines applied to the electric-machine compensators allow ensuring the operation of the nonsalient - pole compensator at equal values of output and consumed reactive power. For this purpose the compensator shall be of an asynchronized design. The asynchronized nonsalient-pole compensators differ from the synchronous ones by availability of an additional field winding along the rotor quadrature. In this case the magtetomotive force ( $\mathrm{mmf}$ ) of this winding may be realized in smaller value in comparison with the main field mmf. At the proper regulation of the compesator excitation, mmf for the rotor quadrature winding may not exceed $6 \%$ of the main winding mmf. In the Electrosila designs concerning the 100 Mvar asynchronized compensators the quadrature winding was calculated for mmf equal to $6 \%$ of the direct field winding $\mathrm{mmf}$. A short-time current forcing in the quadrature winding allows improving of the operation of this winding twice, that gives a high level of the ACK dynamic stability in comparison with the synchronous compensator

The asynchronized compensators are realized like a turbogenerator with a horizontal position of the rotor axis and with a speed of the rotor rotation $1500 \mathrm{rpm}$. The rated line voltage of the stator winding is $20 \mathrm{kV}$ at a possible operation of the compensator with a voltage rise up to $24 \mathrm{kV}$ in the node of connection to the system (Fig. 6).

In the developed designs it is foreseen to cool the asynchronized compensator completely with air that differs from the produced salient-pole synchronous compensators of the same power cooled with hydrogen

In the Table 2 one can find parameters of the 100 Mvar asynchronized compensator. Now we are developing the designs of 50 and 160 Mvar asynchronized compensators.

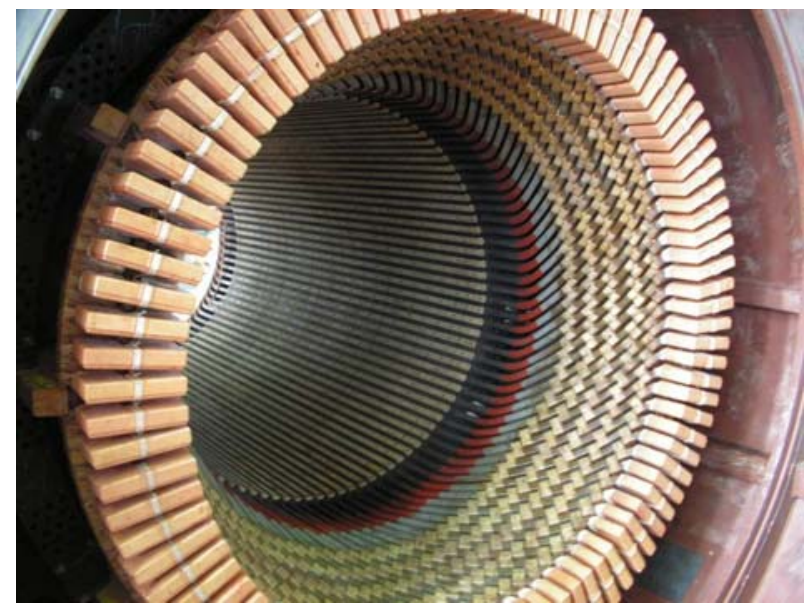

Fig.6. Stator with winding of the asynchronized compensator 100 Mvar
TABLE 2. Design Parameters of 100 Mvar Asynchronized Compensator

\begin{tabular}{|c|c|c|}
\hline Parameter & Unit & Values \\
\hline $\begin{array}{l}\text { Rated reactive power under the } \\
\text { power output mode }\end{array}$ & Mvar & 100.0 \\
\hline $\begin{array}{l}\text { Rated reactive power under the } \\
\text { power consumption mode }\end{array}$ & Mvar & 100.0 \\
\hline $\begin{array}{l}\text { Connection of stator winding / } \\
\text { number of stator phases }\end{array}$ & & $\operatorname{star} / 3$ \\
\hline Stator winding rated line voltage & $\mathrm{kV}$ & 20.0 \\
\hline $\begin{array}{l}\text { Diameter / length of the rotor } \\
\text { active part }\end{array}$ & $\mathrm{mm}$ & $\begin{array}{c}1650 / \\
3300\end{array}$ \\
\hline Stator rated current & A & 2900 \\
\hline Number of pole pairs & & 2 \\
\hline Rotor speed of rotation & $\mathrm{rpm}$ & 1500 \\
\hline $\begin{array}{l}\text { Rated current of direct / quadrature } \\
\text { axis field windings under the } \\
\text { reactive output mode }\end{array}$ & A & $\begin{array}{c}2200 / \\
750\end{array}$ \\
\hline $\begin{array}{l}\text { Ratio of equivalent number of } \\
\text { turns of the quadrature axis and } \\
\text { inducting field winding }\end{array}$ & & 0.18 \\
\hline $\begin{array}{l}\text { Ratio of m.m.f. rated values of the } \\
\text { quadrature axis winding to the } \\
\text { direct (longitudinal) axis winding } \\
\text { under the rated current density }\end{array}$ & $\%$ & 6.0 \\
\hline $\begin{array}{l}\text { The quadrature axis field winding } \\
\text { voltage under the rated current } \\
\text { density / under the } 2.5 \text { times } \\
\text { voltage forcing }\end{array}$ & $\mathrm{V}$ & $18.5 / 45$ \\
\hline $\begin{array}{l}\text { Evaluation of the compensator } \\
\text { total losses at the rated load being } \\
\text { operated under the reactive power } \\
\text { output mode }\end{array}$ & $\mathrm{kW}$ & 1400 \\
\hline
\end{tabular}

\section{A. Compensator Functions:}

- $\quad$ normalization of the voltage value in the electric networks under static and dynamic modes;

- $\quad$ increase of the transmission capacity of separate transmission lines, transmission lines of great extension between systems and between countries;

- $\quad$ purposeful correction of distribution of power flows along the voltage circuits of different classes in multiplecircuit electric networks aimed at reaching a certain technical and commercial effect;

- decrease of power losses in distributing electric lines and backbone transmission lines;

- $\quad$ increase of stability of the power grids.

\section{B. Main Advantage of Asynchronized Compensators:}

- widening of the consumed reactive power range up to the rated value of the compensator power; 
- $\quad$ short-time reactive power output (or consumption) to the electric network under dynamic modes being double in comparison with the rated power;

- $\quad$ high quick-action at regulation of reactive power (voltage) that makes better the character of progress of transients in the system.

\section{Experimental Investigations}

The first of type ТЗФА-110-2 asynchronized turbogenerator was subjected to acceptance tests at the Electrosila factory test rig in 2003 and then was subjected to the commissioning tests at the Thermal Power Station in Moscow. The results of experimental determination of the type T3ФА-110-2 asynchronized machine and type T3Ф-110-2 synchronous machine particular losses and efficiency conducted at the factory test rig are given in Table 3 .

TABLE 3. Results of the Losses Experimental Determination

\begin{tabular}{|c|c|c|}
\hline Losses description & $\begin{array}{c}\text { T3ФА- } \\
110-2, \%\end{array}$ & $\begin{array}{c}\text { T3Ф-110- } \\
2, \%\end{array}$ \\
\hline Rated power, MW & 110 & 110 \\
\hline Rated power factor, p.u. & 0.95 & 0.8 \\
\hline Mechanical losses, \% & 52 & 46 \\
\hline Iron losses, \% & 13 & 18 \\
\hline Short-circuit losses, \% & 13 & 20 \\
\hline Excitation losses, \% & 22 & 16 \\
\hline Total losses, $\%$ & 100 & 100 \\
\hline
\end{tabular}

From the Table 3 you can see that the mechanical losses are rather considerable that is characteristic of the aircooled machines. For asynchronized generator this losses higher in consequence of greater rotor diameter and more intensive ventilation. Along with the abovesaid, it shall be noted that the excitation losses in the asynchronized machine are $70 \%$ higher than the iron losses and shortcircuit losses. The reasons of such relationship are in the asynchronized machine design features described above.

In addition to the tests under the indirect conditions, the back-to-back testing with loading machine (Fig.7) under the relevant conditions determined by capability curves both with reactive power production and consumption have been conducted at the factory test rig. As a loading machine the use was made of type ТЗФГ-160-2 synchronous turbogenerator with a rated output of 160 MW. The maximum reactive-power consumption during the tests amounted to 110 MVAr. The temperature level in the machine active parts under all testing conditions was determined. It was established that at nominal temperature of the cooling air the stator and rotor windings temperature does not exceed the admissible heating for thermal classification B. At the same time with the field current being the rated one the heating of the rotor upper and lower windings differ by $16^{\circ} \mathrm{C}$, that is specified by the asynchronized turbogenerator design features and cooling system. The high efficiency of the

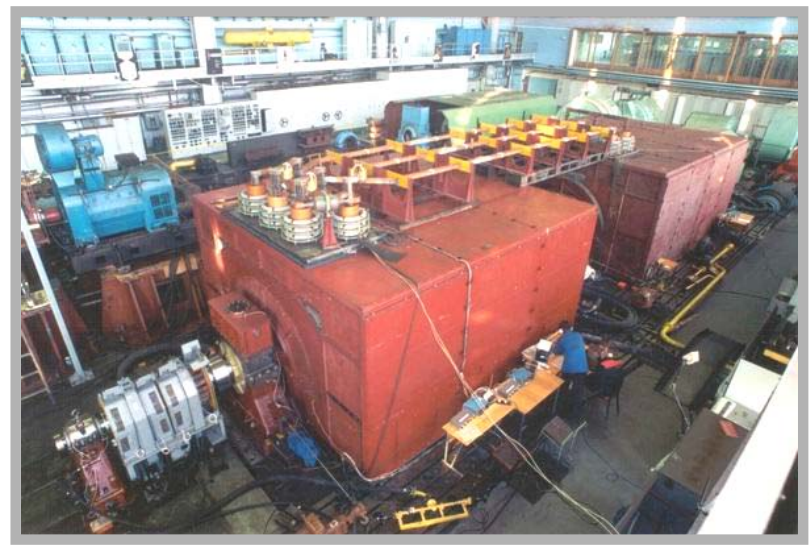

Fig. 7. Type ТЗФ-110-2 asynchronized turbogenerator at the rig tests under the back-to-back loading duty.

stator end zone ventilation is confirmed as well as it is found that the maximum heating of the stator clamping ring corresponds to duty with the reactive power maximum consumption.

\section{Conclusion}

The asynchronized turbogenerators are capable of operating under the duty of the reactive-power deep consumption and find the more wide use in the Russian power systems in order to improve the electric power supply quality and reliability as well as to remove the impermissible overloads from the traditional synchronous generators.

The Branch Electrosila of the JSC Power Machines has developed the air-cooled asynchronized turbogenerators with an output capacity from $110 \mathrm{MW}$ to $320 \mathrm{MW}$ of two modifications: the classical asynchronized design with two symmetrical field windings and the design with a less powerful control winding. The turbogenerators with two symmetrical field windings have the relatively high masses and overall dimensions, but possess the improved reliability. The turbogenerators equipped with the control winding in their mass and overall dimensions and efficiency are close to traditional synchronous machines.

The experience of work of Branch Electrosila of OJSC Power Machines in St. Petersburg on manufacture of asynchronized turbogenerators with double-way feed shows the possibility of manufacturing the asynchronized compensators having the improved operational characteristics in comparison with salient-pole synchronous compensators. In additions they provide higher electric power quality in comparison with static compensators. Implementation of these developments in the required nodes of the power system will eliminate the excess or deficiency of the reactive power, providing the voltage stabilization, and will improve the passing of dynamic modes in the appropriate nodes of the electric system.

The test results and the experience of the failure-free operation have confirmed the correctness of calculations and embodiment. 